\title{
OPTIMIZATION OF THE OXIDATIVE CRACKING OF FUEL OIL ON CATALYSTS OBTAINED FROM KAZAKHSTAN RAW MATERIALS
}

\author{
T.V. Shakiyeva ${ }^{1}$, L.R. Sassykova ${ }^{2,}$, U. N. Dzhatkambayeva ${ }^{1}$, A.A. \\ Khamlenko $^{2}$, N.K. Zhakirova ${ }^{2}$, A.A. Batyrbayeva ${ }^{2}$, R. N. Azhigulova ${ }^{2}$, Sh. N. \\ Kubekova $^{3}$, Zh. M. Zhaxibayeva ${ }^{4}$, M. A. Kozhaisakova ${ }^{5}$, L. A. Zhusupova ${ }^{6}$, \\ S. Sendilvelan ${ }^{7}$ and K. Bhaskar ${ }^{8}$ \\ ${ }^{1}$ Scientific and Production Technical Center "Zhalyn" LLP, Almaty-050012, Kazakhstan \\ ${ }^{2}$ Al-Farabi Kazakh National University, Almaty-050040, Kazakhstan \\ ${ }^{3}$ Satbayev University, Kazakh National Research Technical University after K.I. Satpayev, \\ Almaty-050013, Kazakhstan \\ ${ }^{4}$ Abai Kazakh National Pedagogical University, Almaty-050000, Kazakhstan \\ ${ }^{5}$ Almaty Technological University, Almaty-050012, Kazakhstan \\ ${ }^{6}$ Korkyt Ata Kyzylorda State University, Kyzylorda-120000, Kazakhstan \\ ${ }^{7}$ Department of Mechanical Engineering, Dr.M.G.R. Educational and Research Institute, \\ University, Chennai-600095, Tamilnadu, India \\ ${ }^{8}$ Department of Automobile Engineering, Rajalakshmi Engineering College, Chennai-602105, \\ India \\ ${ }^{\square}$ Corresponding Author: larissa.rav@mail.ru
}

\begin{abstract}
This study aimed to prepare catalysts on the base of Kazakhstan raw materials and test them in the oxidative catalytic cracking of fuel oils. It was determined the influence of air on the route of cracking reactions and establish the relationship between the parameters of oxidative catalytic cracking and the degree of conversion of high molecular weight hydrocarbons to light products. It was found that the air additives contribute to a deeper degradation of hydrocarbons of the starting material. According to the IR spectra, the oxidative cracking gasoline carried out without a catalyst contains sulfur compounds bound to the oxygen atom $\left(927-1,007 \mathrm{~cm}^{-1}\right)$ and carbon $\left(747 \mathrm{~cm}^{-1}\right)$. With an increase in the volumetric flow rate of air and processed feedstock, in the presence of a catalyst, sulfur-containing hydrocarbons are likely to be oxidized. The introduction of air additives into the reactor increases the fraction of the dehydrogenation reaction for lighter-boiling hydrocarbons (fraction $185-340^{\circ} \mathrm{C}$ ) and does not affect the degree of dehydrogenation of the heavier fraction. The addition of air oxygen to the reactor when carrying out catalytic cracking on the developed catalysts makes it possible to deepen the processing of fuel oil and significantly reduce the content of sulfur-containing compounds. The presence of a catalyst promotes their destruction and removal from the gasoline fraction.

Keywords: Catalytic Cracking, Oil Fuel, Gasoline, Natural Taizhuzgen Zeolite, Narynkol Clay, Water and Gas Purification, Highly Toxic Organic Compounds.
\end{abstract}

RASĀYAN J. Chem., Vol. 14, No.2, 2021

\section{INTRODUCTION}

Catalytic cracking is one of the most important multi-tonnage processes of modern oil refining. It allows you to get motor fuels and petrochemical raw materials from heavy oil raw materials of various quality. The constantly increasing demand for motor fuels and other products of catalytic cracking, as well as the limited resources of raw materials, make it necessary to intensify the process. ${ }^{1-6}$ The most "vulnerable" place that restricts intensive processing of heavy raw materials is increased coking. In developed countries, the main areas of intensification of catalytic cracking are the development of highly efficient catalytic systems, reconstruction of installations and various methods of preliminary preparation of raw 
materials. ${ }^{7-10}$ These methods give good results but require high costs for research, development and implementation of results.

When carrying out catalytic cracking, several sequentially - parallel reactions take place, in which both the molecules of the feedstock and the molecules formed during the reaction participate. The mechanism of most reactions of catalytic cracking is described qualitatively within the framework of the carboniumion theory. ${ }^{11-17}$ Since catalytic cracking is a chain reaction, the process can be intensified by initiating radical chain reactions on the catalyst surface with various additives. The principles of new technological processes for the processing of fuel oil and liquid bitumen include the use of ozonolysis and radiolysis. ${ }^{18-}$ ${ }^{21}$ The effectiveness of the effect of ozone on the conversion of fuel oil under the conditions of its visbreaking process and the possibility of reducing the temperature to $425-450^{\circ} \mathrm{C}$ was shown. ${ }^{22-24} \mathrm{The}$ large conversion depth of ozonized fuel oil is due to the appearance in the system, in addition to hydrocarbon radicals, of peroxide radicals formed as a result of the decomposition of ozonolysis products of fuel oil components. After processing the gasoline fraction of ozonated oil on a zeolite-containing catalyst, the quality of the produced gasoline is improved and their yield is significantly increased in comparison with similar processing of the corresponding fraction of crude oil. The content of aromatic hydrocarbons in the catalysts decreases and the proportion of $\mathrm{C}_{5}$ isoalkanes increases, while the octane numbers change insignificantly. ${ }^{24,25}$ The observed changes in the hydrocarbon composition of gasolines are a good prerequisite for obtaining more environmentally friendly fuel.

The process of cracking of a vacuum distillate on a zeolite-alumino-silicate catalyst and reforming of gasoline fractions on a modified catalyst in the presence of atmospheric oxygen with its concentration in the reactor below the lower explosive limit of the reaction mixture was studied.${ }^{25} \mathrm{Catalytic}$ cracking of the vacuum distillate was carried out in a laboratory flow-through setup at atmospheric pressure, in an inert atmosphere and in the presence of air, which was supplied in an amount ensuring the oxygen content in the reaction mixture was not more than $5 \% \mathrm{wt}$. for raw materials. The presence of oxygen contributed to an increase in the yield of light fractions, however, it leads to an increase in the yield of hydrocarbon gases (to the least extent at an oxygen content of $1.3 \mathrm{wt}$ \%), as well as the coke content on the catalyst. The gasoline fraction obtained in the presence of oxygen has a higher octane number (by 1.5-2.3 units) than the same fraction obtained in the absence of oxygen. This can be explained by the presence of oxygen-containing hydrocarbon compounds in it, which is confirmed by IR spectra. On the results of oxidative catalytic cracking (oxycracking) of vacuum gas oil in the presence of an industrial zeolite catalyst "omnikat", it was found that the oxidation state of hydrocarbon feedstock in the range of 0.5 $1.0 \%$ promotes an increase in the yield of gasoline fraction (up to $25-27 \%$ ) at increasing the depth of its transformation by $14-15 \%$ of the mass ${ }^{26,27}$ The presence of air in the reaction mixture changes the route of the reactions occurring during cracking. Unlike an inert atmosphere, where the isomerization reaction of $\mathrm{n}$-alkanes (57\% of isoalkanes) is predominant, the oxidative destruction of vacuum gas oil enhances the process of dehydrogenation of its constituent paraffin to olefinic hydrocarbons.

So, when comparing the technological characteristics of the oxidative cracking of heavy petroleum fractions on composites of natural components with the well-known industrial processes of catalytic cracking of petroleum residues, the advantage of using air additives in the reactor during catalytic cracking becomes obvious. ${ }^{20-27}$

This work aimed to study the patterns of oxidative cracking of fuel oils on composite catalysts based on Kazakhstan's natural raw materials.

\section{Material and Methods}

\section{EXPERIMENTAL}

Commodity fuel oil and a fuel oil of the M-100 brand of the Amangeldy gas processing plant (Kazakhstan) were used as raw materials for cracking. The natural zeolite of Taizhuzgen deposit and clay of Narynkol deposit were applied for the synthesis of zeolite-containing catalysts. Initially, fractions of zeolite and clay of 60-80 microns were prepared. The zeolite was activated by ion exchange of sodium cations from the zeolite framework into lanthanum and ammonium cations.

The experimental procedure, preparation of catalysts, and general information on the starting materials are described in our previous work. ${ }^{28,29}$ The analysis of gaseous cracking products was carried out on a 
gas chromatograph with a flame ionization detector: for hydrocarbon gases - on columns, $2 \mathrm{~m}$ long and 2 $\mathrm{mm}$ in inner diameter filled with a porralak sorbent with particle sizes $8.2-8.3 \mathrm{~mm}$; for non-hydrocarbon gases - on a packed column $1 \mathrm{~m}$ long with $\mathrm{NaX}$ zeolite with a particle size of $0.25-0.5 \mathrm{~mm}$. The carrier gas, argon, was supplied at a rate of $3 \mathrm{ml} / \mathrm{min}$. The programmed temperature scan was performed for hydrocarbon gas in the range $-25-165^{\circ} \mathrm{C}$ with exposure at $25^{\circ} \mathrm{C}$ for 7 minutes; and for non-hydrocarbon gas $-40-100^{\circ} \mathrm{C}$, at a speed of $8^{\circ} \mathrm{C} / \mathrm{min}$.

The spectra of the sample were registered on the JNN-ECA 400 spectrometer of the company "Jeol" (Japan). The operating frequency of the spectrometer is 400 and $100 \mathrm{MHz}$ on ${ }^{1} \mathrm{H}$ and ${ }^{13} \mathrm{C}$ cores, respectively. The survey was performed at room temperature using $\mathrm{CDCl}_{3}$ solvent. Chemical shifts are measured relative to the signals of residual protons or carbon atoms of deuterated chloroform. ${ }^{30,31}$

\section{RESULTS AND DISCUSSION}

According to NMR research, the proton spectrum of Amangeldy fuel oil (Fig.-1) contains ${ }^{1} \mathrm{H}$ signals of paraffinic, naphthenic and aromatic compounds, which are the main components of the mixture. Signals of methyl protons of saturated hydrocarbons $(\mathrm{HC})$ are noted as a broadened singlet at $0.90 \mathrm{ppm}$. A highintensity signal with a chemical shift of $1.28 \mathrm{ppm}$ indicates a high content of protons of methylene groups of aliphatic cyclic and acyclic hydrocarbons.

A small amount of $\mathrm{CH}_{3}$ groups was noted in the $\alpha$-position to the aromatic ring $(\delta=2.30-2.63 \mathrm{ppm})$. In the range of 2.70-4.50 ppm probably the resonance of protons of the $\mathrm{CH}_{2}$ and $\mathrm{CH}$ groups in the $\alpha$-position of aromatic systems. ${ }^{6,28,30,31}$

Of great practical interest is the development of effective technology for catalytic cracking of fuel oil without pre-desulfurization and demetallization of heavy raw materials, which are used in industrial processes. ${ }^{32-37} 84.5$ wt. $\%$ of the weight of fuel oil is made up of vacuum distillate and heavier fractions (Table-1).

Table-1: Commercial Fuel Oil: Composition and Sulfur Content

\begin{tabular}{l|c|c}
\hline \multicolumn{1}{c|}{ Content, wt. \% } & Components & Sulfur Content \\
\hline Fuel oil & 100.00 & 2.10 \\
\hline Gasoline & 0.50 & - \\
\hline Light gas oil & 15.00 & - \\
\hline Vacuum gas oil & 44.80 & - \\
\hline Heavy residue & 39.70 & - \\
\hline
\end{tabular}

The effect of small amounts of a catalyst containing 14 wt.\% of Taizhuzgen zeolite and 86 wt.\% of Narynkol clay, as well as additives in the reaction zone of air on the cracking of fuel oil is shown in Table-2.

Table-2: Influence of the Catalyst and Air Additives on the Cracking Process of Commercial Fuel Oil (in Suspension $=0.1 \mathrm{~h}-1 ; 0.2 \mathrm{wt} . \%$ in the Raw Material of a $14 \%$ Composite, $\mathrm{T}=450{ }^{\circ} \mathrm{C}$ )

\begin{tabular}{|c|c|c|c|c|}
\hline \multirow[t]{4}{*}{ Yield, wt.\% } & \multicolumn{4}{|c|}{ Technological Mode } \\
\hline & \multicolumn{4}{|c|}{ Air Presence } \\
\hline & \multicolumn{2}{|c|}{ Inert Atmosphere } & \multicolumn{2}{|c|}{$\mathrm{W}_{\text {air }}=0.05 \mathrm{~h}^{-1}$} \\
\hline & Without Catalyst & With Catalyst & Without Catalyst & With Catalyst \\
\hline Gas & 6.50 & 7.60 & 12.90 & 13.60 \\
\hline Petrol & 3.50 & 4.00 & 5.40 & 13.50 \\
\hline Light gas oil & 19.60 & 22.10 & 19.80 & 55.30 \\
\hline Heavy residue & 68.90 & 64.80 & 6.60 & 13.60 \\
\hline Coke & 1.50 & 1.50 & 1.30 & 4.00 \\
\hline Losses & 0.00 & 0.00 & 0.00 & 0.00 \\
\hline Total & 100.00 & 100.00 & 100.00 & 100.00 \\
\hline
\end{tabular}

As can be seen from Table-2, during thermal cracking of fuel oil, as well as catalytic cracking in an inert atmosphere, gasoline is formed in insignificant amounts, and the yield of light gas oil is 19.6-22.1 wt. \%. In oxidative cracking in the absence of a catalyst, gas formation doubles, but the yield of light products does not change. Consequently, neither air additives nor the catalyst, taken separately, significantly 
RASĀYAN J. Chem.

Vol. 14 | No. 2 |1065-1071| April - June | 2021

activate the process of destruction of high-molecular-weight fuel oil hydrocarbons. With their simultaneous action, i.e. with oxidative catalytic cracking, the yield of both gasoline and kerosenegasoline fractions, and coke, increases 2.5 times.
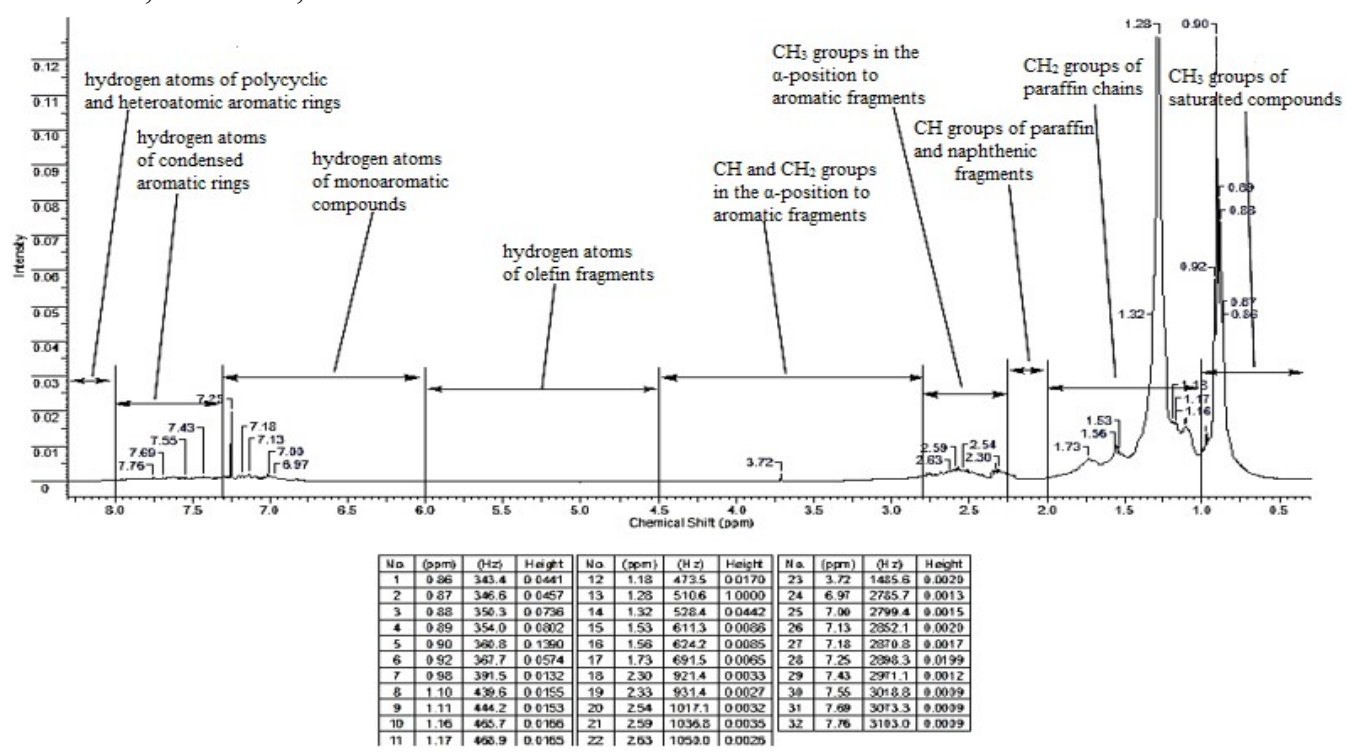

(a)
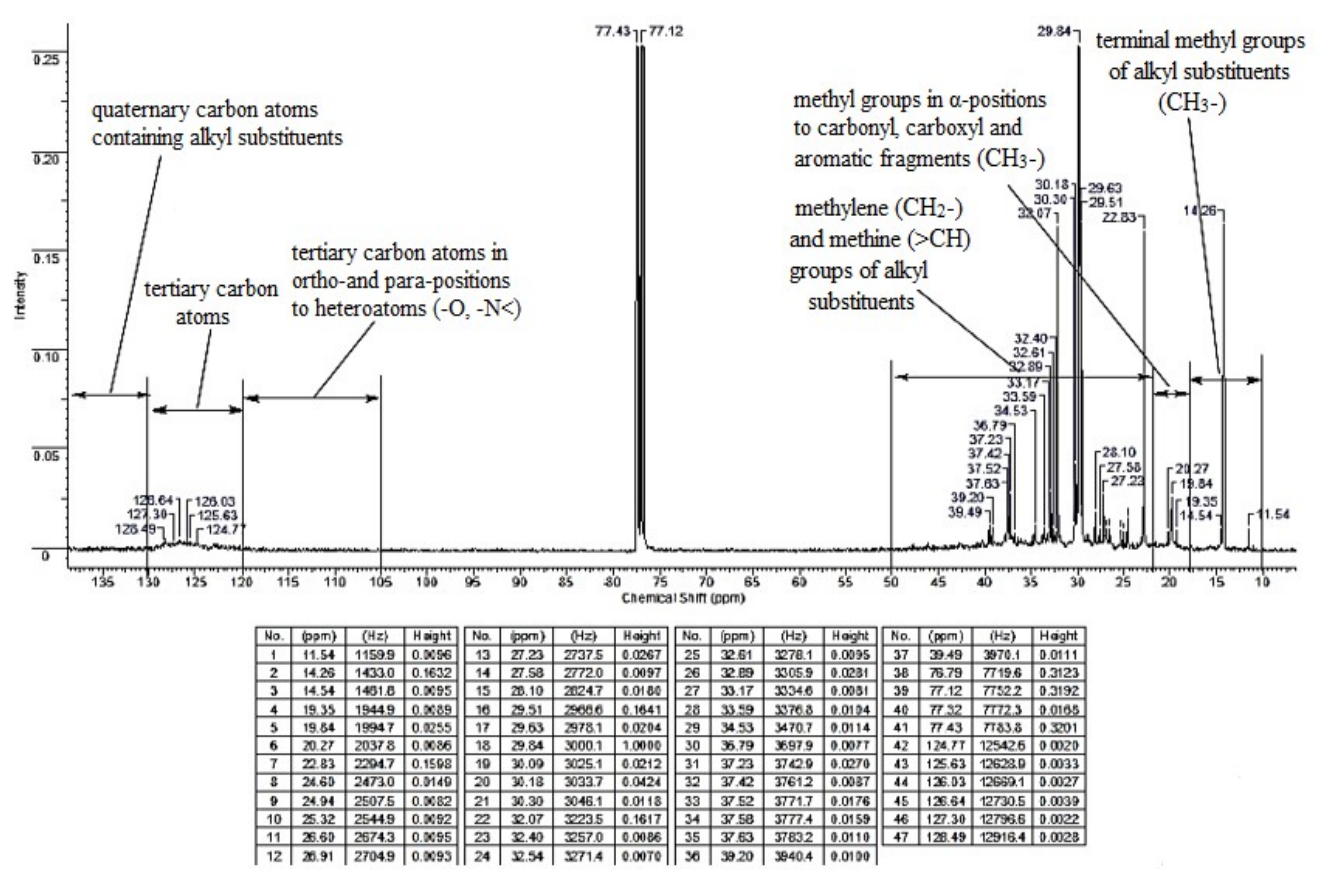

(b)

Fig.-1: NMR spectra of Amangeldy fuel oil: (a) ${ }^{1} \mathrm{H}$ spectrum, (b) ${ }^{13} \mathrm{C}$ Spectrum.

Data on the effect of the concentration of air in the reaction mixture on the cracking of fuel oil under conditions of a high feed rate of its suspension with a composite catalyst into the reactor are presented in Table-3.

The highest yield of gasoline and light gas oil is observed when air is supplied at a speed of $0.15 \mathrm{~h}^{-1}$, and an increase in the concentration of processed raw materials suppresses the destruction of high-molecular 
RASĀYAN J. Chem.

Vol. 14 | No. 2 |1065-1071| April - June | 2021

hydrocarbons that are part of fuel oil to light hydrocarbons of gas and gasoline fractions. At the same time, the yield of the kerosene-gas oil fraction decreases slightly with an increase in the volume rate of its supply. At high concentrations in the reaction mixture of air, intense gas formation begins. Consequently, air additives contribute to a deeper degradation of hydrocarbons of the starting material. The optimal temperature for the process of cracking fuel oil at high speeds of its supply to the reactor is $470{ }^{\circ} \mathrm{C}$.

Since the initial fuel oil cracking (see Table-1) is carried out without preliminary desulfurization, it was of practical interest to determine the characteristics of the resulting products to determine the concentration of sulfur in them (Table-4).

Table-3: Influence of the Volumetric Airflow Rate on the Yield of Cracking Products of Commercial Fuel Oil $\left(\mathrm{W}_{\text {suspension }}=1.0 \mathrm{~h}^{-1}, 0.2 \mathrm{wt} . \%\right.$ in the Raw Material of a $14 \%$ Composite, $\left.\mathrm{T}=450^{\circ} \mathrm{C}\right)$

\begin{tabular}{|c|c|c|c|c|c|c|c|}
\hline \multirow{2}{*}{$\begin{array}{l}\mathrm{W}_{\text {air }} \\
\mathrm{h}^{-1}\end{array}$} & \multicolumn{6}{|c|}{ Product Yield, wt. \% } & \multirow[t]{2}{*}{ Total } \\
\hline & Gas & Gasoline & Light Gas Oil & Heavy Residue & Coke & Losses & \\
\hline 0.0 & 1.00 & 0.20 & 18.80 & 77.60 & 2.40 & 0.0 & 100.0 \\
\hline 0.03 & 4.40 & 1.50 & 25.20 & 67.60 & 1.30 & 0.0 & 100.0 \\
\hline 0.05 & 2.70 & 1.50 & 27.30 & 66.10 & 2.40 & 0.0 & 100.0 \\
\hline 0.07 & 3.20 & 1.20 & 39.00 & 54.70 & 1.90 & 0.0 & 100.0 \\
\hline 0.10 & 3.30 & 1.40 & 39.30 & 53.90 & 2.10 & 0.0 & 100.0 \\
\hline 0.15 & 1.10 & 3.00 & 42.70 & 51.70 & 1.50 & 0.0 & 100.0 \\
\hline 0.50 & 6.00 & 1.80 & 23.40 & 67.50 & 1.30 & 0.0 & 100.0 \\
\hline 0.70 & 10.60 & 1.10 & 38.00 & 49.00 & 1.30 & 0.0 & 100.0 \\
\hline
\end{tabular}

Table-4: Sulfur Content in Kerosene-Gas Oil Cracking Fractions of Commercial Fuel Oil at $470^{\circ} \mathrm{C}$

\begin{tabular}{c|c|c|c|c}
\hline \multirow{2}{*}{ No } & \multirow{2}{*}{ Catalyst } & \multirow{2}{*}{$\mathrm{W}_{\text {air }}, \mathrm{h}^{-1}$} & \multicolumn{2}{|c}{$\begin{array}{c}\text { Sulfur Concentration (wt. \%) in Fractions } \\
\text { of Light Gas Oil, } \mathrm{T}_{\text {initial boiling point }}\end{array}$} \\
\cline { 4 - 5 } & & & $185-340^{\circ} \mathrm{C}$ & $340-350^{\circ} \mathrm{C}$ \\
\hline 1 & without catalyst & 0 & 0.2 & 0.2 \\
\hline 2 & without catalyst & 0.15 & 0.2 & 0.4 \\
\hline 3 & with catalyst & 0.15 & 0.1 & 0.4 \\
\hline
\end{tabular}

Comparing the results of the experiment (Table-4) and the initial raw material data (Table-1), it can be seen that the sulfur content in the kerosene-gas oil fraction, boiling at $185-340^{\circ} \mathrm{C}$, is 20 times, and in the fraction $340-350^{\circ} \mathrm{C}-5$ times less, than in the original fuel oil.

It should be noted that in gasoline of oxidative cracking carried out at $450^{\circ} \mathrm{C}$ in the absence of a catalyst, compounds of sulfur bound to the oxygen atom $\left(927-1,007 \mathrm{~cm}^{-1}\right)$ and carbon $\left(747 \mathrm{~cm}^{-1}\right)$ were identified. ${ }^{38-}$ ${ }^{41} \mathrm{With}$ an increase in the volume rate of air input and the raw material, in the presence of a catalyst, sulfur-containing hydrocarbons are likely to be oxidized. This is evidenced by the disappearance of the absorption band at $747 \mathrm{~cm}^{-1}$, which is characteristic of valence vibrations of the C-S bond; as well as the appearance of a band at $940 \mathrm{~cm}^{-1}$, showing the presence of sulfoxides in the test sample. Under the conditions of catalytic cracking in an inert atmosphere, sulfur compounds are not contained in the resulting gasoline. It can be concluded that these sulfur compounds do not oxidize, while the presence of a catalyst contributes to their destruction and removal from the gasoline fraction. For hydrocarbons of kerosene-gas oil fractions, unlike gasoline, the oxidation of sulfur-containing hydrocarbons does not occur completely, since the spectrum contains lines that characterize the $\mathrm{S}_{-} \mathrm{CH}_{2}$ bond $\left(2,627\right.$ and $740 \mathrm{~cm}^{-}$ $\left.{ }^{1}\right)$. Moreover, when air is added to the reaction zone, the intensity of the absorption band at $920 \mathrm{~cm}^{-1}$ corresponding to the valence vibrations $\mathrm{S}-\mathrm{O}$ and $\mathrm{S}=\mathrm{O}$, increases. Based on IR spectral analysis, the course of dehydrogenation reactions of alkanes to olefins during oxidative cracking of fuel oil was established.

\section{CONCLUSION}

The article is devoted to developing catalysts based on natural Taizhuzgen zeolite and Narynkol clay (Kazakhstan) and testing their efficiency in the catalytic cracking of fuel oil. It was shown that the highest yield of gasoline and light gas oil is observed when air is supplied at a speed of $0.15 \mathrm{~h}^{-1}$, and an increase in the concentration of processed raw materials suppresses the destruction of high-molecular 
hydrocarbons that are part of fuel oil to light hydrocarbons of gas and gasoline fractions. The influence of the catalyst and air can be seen not only in the yield of kerosene-gas oil fractions but also in the composition of the hydrocarbons contained in them. In an inert atmosphere in the absence of a catalyst, dehydrogenation of hydrocarbons practically does not occur. A significant decrease in sulfur-containing compounds in the products has been established, the presence of a catalyst promotes their destruction and removal from the gasoline fraction.

\section{ACKNOWLEDGEMENT}

We would like to express sincere gratitude for grant financing by the program: No. AP09260687 "Technology for the recovery and disposal of toxic compounds from industrial wastewater".

\section{REFERENCES}

1. R. Pujro, M. Falco and U. Sedran, Energy \& Fuels, 29(3), 1543(2015), DOI:10.1021/ef502707w

2. A. Scott, Chemical Week, 164(21), 24(2002)

3. P. O'Connor, Studies in Surface Science and Catalysis, 166, 227(2007)

4. I. Amghizar, L. A.Vandewalle and K. M.Van Geem, Engineering, 3(2), 171(2017)

5. D. S.Redwan and S. A. All, Fuel Science and Technology International, 10(2), 141(1992), DOI: $10.1080 / 08843759208915983$

6. L.R. Sassykova, N.K. Zhakirova, Y.A. Aubakirov, S. Sendilvelan, Z.K. Tashmukhambetova, T. S. Abildin, B. D. Balgysheva, A. A. Omarova, M. A. Sarybayev and L. K. Beisembaeva, Rasayan Journal of Chemistry, 13(3), 1444(2020), DOI:10.31788/ RJC.2020.1335822

7. T. M.Murzagaleev, A.K. Golovko, T.A. Feduschak and V.D. Ogorodnikov, Journal of Siberian Federal University. Chemistry, 5(2), 224(2012)

8. I. E. Maxwell and W.H.J. Stork, Studies in Surface Science and Catalysis, 137, 747(2001)

9. E. Derouane and D. J. Vanderveken, Applied Catalysis, 45, 15(1988)

10. S. Fukase and F. Maruyama, Journal of The Japan Petroleum Institute, 37(6), 611(1994), DOI: $10.1627 /$ jpi1958.37.611

11. R. Kh. Salakhov, M. Seitzhanova, D.U. Bodykov, L.R. Sassykova, N.K. Zhakirova and T.M. Seilkhanov, Eurasian Chemico-Technological Journal, 22(4), 315(2020), DOI:10.18321/ectj999

12. J.H. Chen, J.N. Lin, Y. M. Kang, W.Y. Yu, C.N. Kuo and B.Z. Wan, Applied Catalysis A: General, 291(1-2), 162(2005)

13. M. Stocker, Microporous and Mesoporous Materials, 82, 257(2005)

14. V. Blay, E. Epelde, R. Miravalles and L. A. Perea, Catalysis Reviews Science and Engineering, 60, 278(2018)

15. N. Viswanadham, G. Muralidhar and T.S.R. Prasada Rao, Journal of Molecular Catalysis A: Chemical, 223(1-2), 269(2004), DOI:10.1016/j.molcata.2003.11.045

16. L.R. Sassykova, Chemical and Biochemical Engineering Quarterly, 31(4), 447(2017), DOI: 10.15255/CABEQ.2016.959

17. G. Song, De-Hui Wang, Zh. Zhang, M. Liu, Q. Xu and De-Zhi Zhao, Ultrasonics Sonochemistry, 48, 103(2018), DOI:10.1016/j.ultsonch.2018.05.029

18. R.R.Vezirov, I.R.Yavgildin, U.R. Urmantsev, I.R.Khairudinov and E.G. Telyashev, Oil and gas, 2, 9(1997)

19. N. S. Musina and T. A. Maryutina, Journal of Analytical Chemistry, 71(1), 27(2016), DOI: $10.1134 / \mathrm{s} 1061934816010081$

20. S. V. Lesin and V. I. Lesin, Petroleum Chemistry, 58(7), 553(2018)

21. Y. Tanimoto, H. Tanaka, Y. Fujiwara and M. Fujiwara, The Journal of Physical Chemistry A, 102(28), 5611(1998)

22. V.V. Lunin, N.M. Likhterova, V.N.Torichovsky, A.V.Fionov, Yu.N. Gavrish and K.Sh. Ajinomo, Ozone Technology, In Proceedings of 16th World Congress of International Ozone Association, LasVegas, Nevada, U.S.A., p. 12(2003)

23. K. Sh. Ajinomokh, Physicochemical Methods of Activation of Components of Heavy Petroleum Raw Materials, Ph. D. Thesis, Moscow, Russia (2005)

24. N. A. Pivovarova, Neftekhimiya, 59 (7), 727(2019), DOI:10.1134/s002824211907013x 
25. S. I. Kolesnikov, V.O. Zvyagin and I.M. Kolesnikov, Chemistry and Technology of Fuels and Oils, 2, 10(1999)

26. L. A. Mursalova, E. A. Guseinova and K. Yu. Adzhamov, Russian Journal of Physical Chemistry A, 90(8), 1533(2016), DOI:10.1134/s0036024416080197

27. E. A. Guseinova, L. A. Mursalova, N. N. Bagirova and K. Yu. Adzhamov, Petroleum Chemistry, 59(2), 180(2019), DOI:10.1134/s0965544119020075

28. R. Kh. Ibrasheva, V.S. Yemelyanova, L.R. Sassykova, U. N. Dzhatkambayeva, T.V. Shakiyeva, B.T. Dossumova, N.K. Zhakirova, S. Sendilvelan and T. M. Seilkhanov, Rasayan Journal of Chemistry, 13(4), 2370(2020), DOI:10.31788/RJC.2020.1345948

29. V. S. Yemelyanova, B. T. Dossumova, T. V. Shakiyeva, L.R. Sassykova and S. Sendilvelan, International Journal of Mechanical and Production Engineering Research and Development, 9(4), 1079(2019), DOI:10.24247/ijmperdaug2019111

30. T. Cheung, Journal of Catalysis, 124(2), 511(1990)

31. D. Orlicki, U. Navarro, M. Ni and L. Langan, Chemical Industries, 173(2010)

32. B.T. Tuktin, A.S. Tenizbayeva, A.A. Omarova, L.R. Sassykova and Zh.A. Sailau, Rasayan Journal of Chemistry, 12(3), 1478(2019), DOI:10.31788/RJC.2019.1235236

33. S.W. Kim, C.E. Yeo and D.Y. Lee, Energies, 12(2), 293(2019), DOI:10.3390/en12020293

34. S. M. Rigutto, R. Veen and H. Laurent, Studies in Surface Science and Catalysis, 168, 855(2007), DOI: 10.1016/s0167-2991(07)80812-3

35. A. Omarova, L. Sassykova, M. Tulepov and N. Zhakirova, Journal of Chemical Technology and Metallurgy, 54(3), 547(2019)

36. I. Wang, Journal of Catalysis, 60(1), 140(1979)

37. Y.X.Zhao, G.R. Bamwenda and B.W. Wojciechowski, Journal of Catalysis, 142(2), 465(1993)

38. G. D. Zakumbaeva, L. B. Shapovalova, B. T. Tuktin and A.A. Omarova, Petroleum Chemistry, 50(2), 135(2010), DOI: 10.1134/s096554411002009x

39. Zh. Kh. Tashmukhambetova, N.K. Zhakirova, L.R. Sassykova, K. A. Kadirbekov, Y.A. Aubakirov and A.S. Zhumakanova, Oriental Journal of Chemistry, 33(6), 2803(2017)

40. S. Fukase and F. Maruyama, Journal of The Japan Petroleum Institute, 37(6), 611(1994), DOI: $10.1627 /$ jpi1958.37.611

41. C. Senter, M. C. Mastry, A. M. Mannion and R. McGuire Jr., Catalysts, 9(10), 831(2019), DOI: $10.3390 /$ catal9100831

[RJC-6152/2020] 